\title{
Extreme Approach to Optimizing the Process of Electrical Discharge Profiling of Diamond Tool
}

\author{
Olga V. Ermilina ${ }^{1}$, Vladimir B. Chemodanov ${ }^{2}$ \\ ${ }^{1}$ Penza State University, 440026, Krasnaya street, 40, Penza, Russia \\ ${ }^{2}$ Moscow Aviation Institute (MAI), 125993, Volokolamskoe highway, 4, Moscow, Russia
}

\begin{abstract}
The process of electrical discharge profiling of diamond tool is regarded as a stochastic control object from the point of view of the analysis of factors affecting its productivity. The selection of optimal modes can significantly improve the quality indicators of this process. For this improvement, a model of electrical discharge profiling is developed using the example of diamond grinding wheels, which allows making an informed selection of optimal control modes for this process. The main factor that reduces productivity is the insufficient average power released in the interelectrode gap during electrical discharge machining of the workpiece. The dependence of the indicated power on the size of the interelectrode gap and on the frequency and amplitude of technological pulses is extreme, which determines the choice of approach to optimizing the process. To ensure extreme power control, it is proposed to use the Gauss-Seidel coordinate descent method for two parameters: the size of the interelectrode gap and the amplitude of the pulse generator. The search algorithm for the extremum of the static characteristics of the inertial object for each coordinate is performed with the help of the recursive least squares method.
\end{abstract}

Keywords - extreme control, objective function, electrical discharge profiling, diamond tool, interelectrode gap, static characteristics, phase trajectory.

DOI: 10.18421/TEM92-14

https://doi.org/10.18421/TEM92-14

Corresponding author: Vladimir B. Chemodanov, Moscow Aviation Institute (MAI), Moscow, Russia. Email: chemodanov.vladimir b@mail.ru

Received: 28 February 2020.

Revised: 01 April 2020.

Accepted: 07 April 2020.

Published: 27 May 2020.

(c))BY-NC-ND (C) 2020 Olga V. Ermilina \& Vladimir B. Chemodanov; published by UIKTEN. This work is licensed under the Creative Commons AttributionNonCommercial-NoDerivs 3.0 License.

The article is published with Open Access at www.temjournal.com

\section{Introduction}

Electrical discharge profiling is widely used in various machine building industries, though it has a significant drawback: insufficient productivity [1]. The selection of optimal operating modes will largely overcome it.

In order to obtain more complete information on the nature of the power behavior in the interelectrode gap during electrical discharge profiling, experimental studies were conducted on the influence of the size of this gap on the average power released in it (Figure 1.) for various values of the duty cycle of technological pulses $q$.

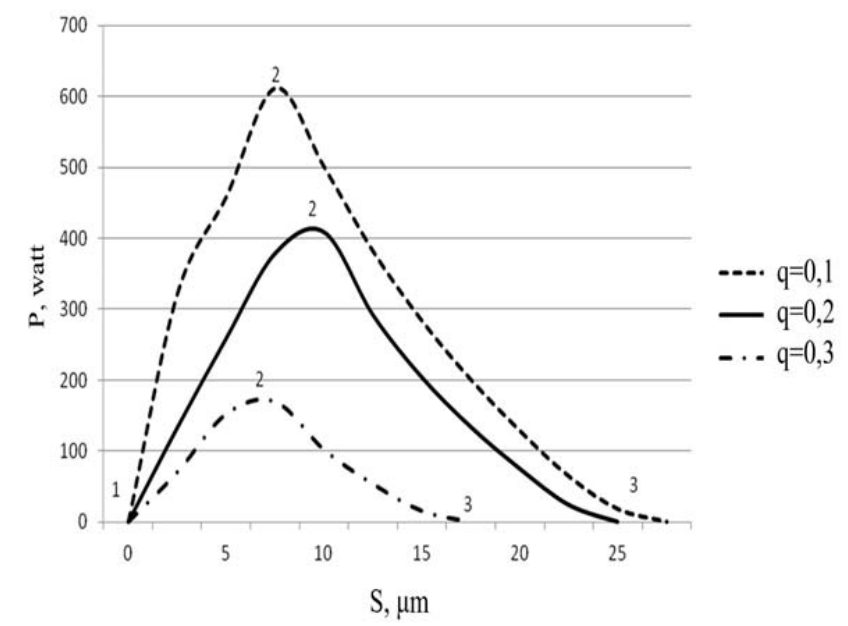

Figure 1. Dependences of the average power released in the interelectrode gap on the size of this gap

Figure 1. shows that in section 1-2 the power released in this gap increases sharply from zero to a maximum with an increase in the interelectrode gap. This is explained by the fact that with an increase in the gap, the number of short circuit pulses sharply decreases, and the number of working pulses that remove material from the workpiece during profiling increases. A sharp decrease in the number of short circuit pulses is associated with more intensive removal of conductive erosion products from the interelectrode gap. With an increase in the number of working pulses, the average voltage of the pulses 
also increases, which leads to an increase in the average power released in the interelectrode gap.

In the extremum section, the number of working pulses reaches its maximum, which leads to an increase in average power.

Further increase in the interelectrode gap, in section 2-3, leads to an increase in the number of "idle" pulses, at which there is no spark breakdown of the interelectrode gap, and the average value of the amplitude of the discharge current drops to zero. In this regard, the value of the average power also falls to zero.

On the basis of the studies, the conclusion can be drawn that it is necessary to conduct the process of electrical discharge profiling at the maximum power released in the interelectrode gap to achieve maximum productivity.

The use of extreme control is constrained by the fact that the process of electrical discharge machining is stochastic. This is particularly true for the process of diamond wheels profiling. The complex microrelief of the machined surface, the presence of non-conductive inclusions, the undesirability of graphitization of diamond grains under the influence of the electric current, and the high accuracy of profiling place high demands on the control system of the process of electrical discharge machining [2], [3], [4].

\section{Formulation of the Problem}

Consideration of the technology of the electric discharge machining process allowed establishing that the determining factor affecting the technological indicators is the optimal maintenance of the interelectrode gap [1]. The considered process is also significantly affected by the rational choice of the parameters of the working pulses of the generator, which affects the productivity of the process of electric discharge machining of diamond grinding wheels [5].

For this fact, the following targets were set:

- building a model of electrical discharge profiling of diamond grinding wheels, which allows making an informed selection of algorithms and control modes for this process to increase its productivity;

- development of a noise-resistant high-speed algorithm for finding the extremum of the static characteristics of an inertial object, which allows increasing the accuracy of the technological process in extreme type objects of various inertia, operating in conditions of strong noise;
- synthesis and analysis of the structure of the extreme control system of the electrical discharge

\section{Mathematical Modelling of the Process of the Electrical Discharge Profiling for Diamond Grinding Wheels}

The main difficulty in controlling the process of the electrical discharge profiling for diamond grinding wheels lies in unforeseen changes in a wide range of characteristics of external influences and properties of controlled objects, as well as in the incompleteness of information on these characteristics and properties. Furthermore, the electrical discharge machining process is insufficiently formalized in view of the complexity of the interaction of technological indicators and output values.

For this task, it is proposed to develop a generalized model of the process of the electrical discharge profiling of diamond grinding wheels. As a result of the analysis of the technological process, the generalized model can be divided into three submodels: the model of external disturbances, taking into account the topology of the electrode surfaces and diamond grinding wheels, based on the singular value decomposition of the profile of these surfaces; the electromechanical model of electric drives of an electrical discharge machine built on the basis of a generalized theory of electrical machines; and the electrical model of the interelectrode gap, which describes the physical processes in the interelectrode gap of an electrical discharge machine during profiling.

The process of electrical discharge profiling is studied in detail, the effects of various technological modes of machining on the productivity, accuracy, and quality of the machined surfaces, as well as tool electrode wear are revealed. However, in view of the complexity of the interconnections between the modes of the profiling process and its technological characteristics [6], recommendations for selection of the parameters of discharge pulses are based, first of all, on practical experience and the results of experimental studies.

To identify the profile of the working surface, it was scanned with the profilograph "Seytronik PSH8 SS-4" in a plane passing through the axis of the diamond wheel and perpendicular to the cutting speed vector. Figure 2. shows typical profilodiagrams of the working surface. 


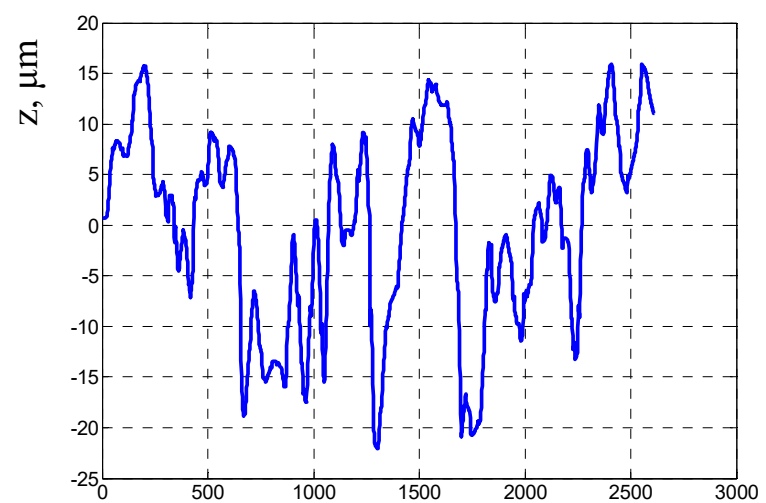

a)

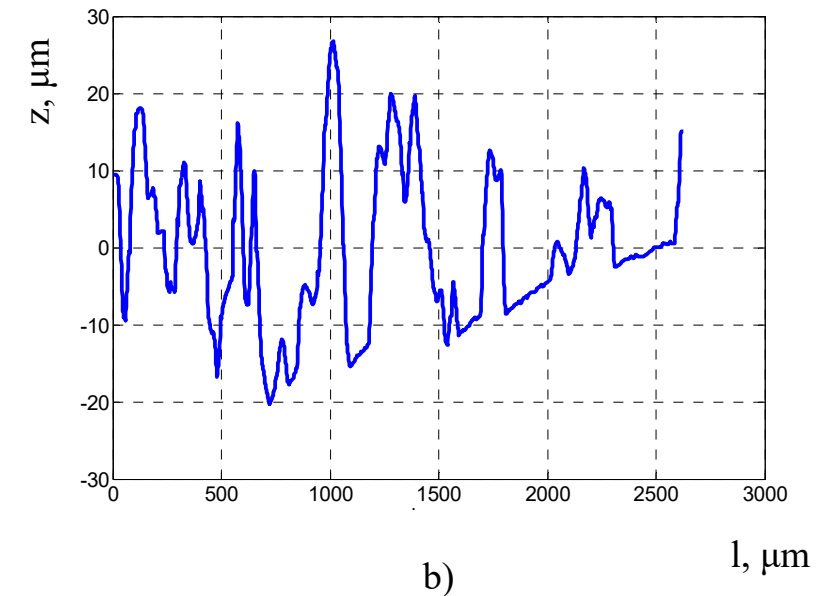

b)

$1, \mu \mathrm{m}$

Figure 2. Profilograms of the working surface of diamond grinding wheel with grain size: (a) 80/63 $\mu \mathrm{m}$; (b) 50/40 $\mu \mathrm{m}$

To model the working surfaces of diamond grinding wheels, it is proposed to use the distinction of trend and periodic components of numerical series within the method of singular value decomposition (SVD-method) that is decomposition of a material matrix in order to put it into canonical form. This method does not provide knowledge of the parametric model of the series and allows working with noisy non-stationary time series. In particular, it allows distinguishing amplitude-modulated harmonic components and, due to this, compares favourably with the methods based on the Fourier decomposition [7]. As a result of it, harmonic components were revealed; no trend components were found in the profilograms.

One of the important parameters for SVD is the selection of the window length $\mathrm{L}$ required for the formation of the initial decomposition matrix. Since the initial numerical series of the experimental profilogram contain periodic components, it was proposed to select the window length multiple of the maximum period of such component. To distinguish periodic components, synchronous storage method was used.

As a result of SVD, 10 eigenvectors for a diamond wheel with a grain size of $80 / 63 \mu \mathrm{m}$ and 12 eigenvectors for a diamond wheel with a grain size of $50 / 40 \mu \mathrm{m}$ were selected.

The eigenvectors were grouped in pairs (by frequency), the formed pairs were summed, and the results were subjected to harmonic analysis. The numerical results of the analysis are given in the Tables 1. and 2.; the graphic results are given in the Figures 3. and 4.

Table 1. Numerical results of the harmonic analysis of eigenvectors

\begin{tabular}{|c|c|c|c|c|}
\hline \multirow{2}{*}{$\begin{array}{c}\text { Number of pairs } \\
\text { of harmonic }\end{array}$} & \multicolumn{4}{|c|}{ Grain size of diamond powder $80 / 63 \mu \mathrm{m}$} \\
\cline { 2 - 5 } & Amplitude $A$ & Period $T$ & Phase $\varphi$ & Standard deviation \\
\hline 1 & 7.4 & 470.6 & 5.94 & 0.6486 \\
\hline 2 & 5.7 & 1077.1 & 5.94 & 0.8581 \\
\hline 3 & 3.2 & 344.8 & 4.64 & 0.6582 \\
\hline 4 & - & - & - & - \\
\hline 5 & 2.1 & 92.7 & 2.5 & 0.0219 \\
\hline
\end{tabular}

Table 2. Numerical results of the harmonic analysis of eigenvectors

\begin{tabular}{|c|c|c|c|c|}
\hline \multirow{2}{*}{$\begin{array}{c}\text { Number of pairs } \\
\text { of harmonic }\end{array}$} & \multicolumn{4}{|c|}{ Grain size of diamond powder $50 / 40 \mu \mathrm{m}$} \\
\cline { 2 - 5 } & Amplitude $A$ & Period $T$ & Phase $\varphi$ & Standard deviation \\
\hline 1 & 7.5 & 387.5 & 4.62 & 0.203 \\
\hline 2 & 5 & 1000 & 6.28 & 0.1068 \\
\hline 3 & 3.8 & 227 & 4.24 & 0.0702 \\
\hline 4 & - & - & - & - \\
\hline 5 & 2.2 & 178.5 & 3.02 & 0.009 \\
\hline 6 & 2 & 115.6 & 3.4 & 0.0131 \\
\hline
\end{tabular}


First pair of harmonics

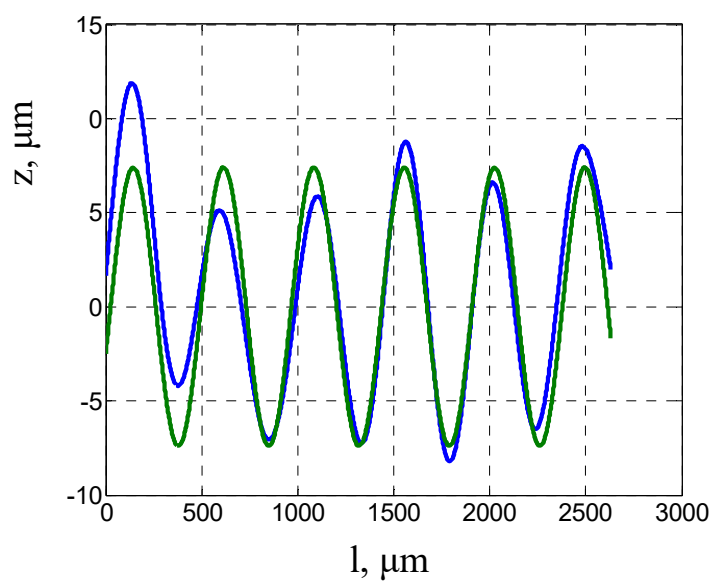

a)

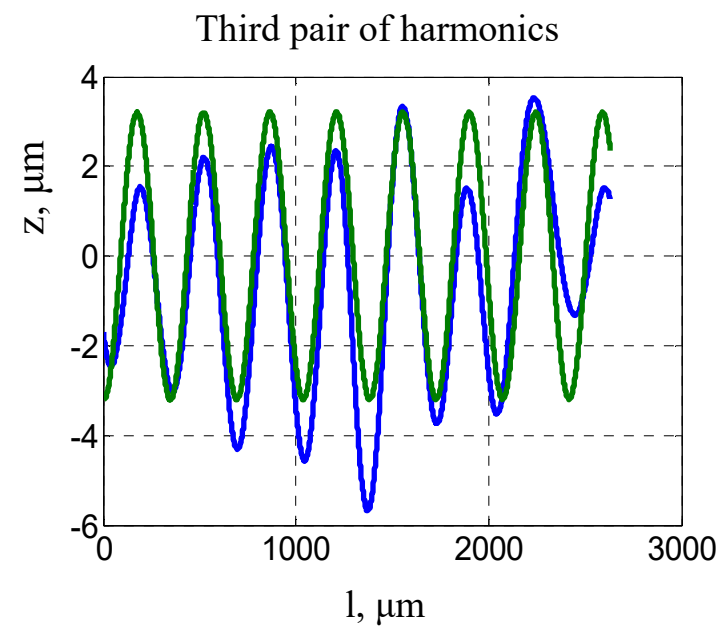

c)
Second pair of harmonics

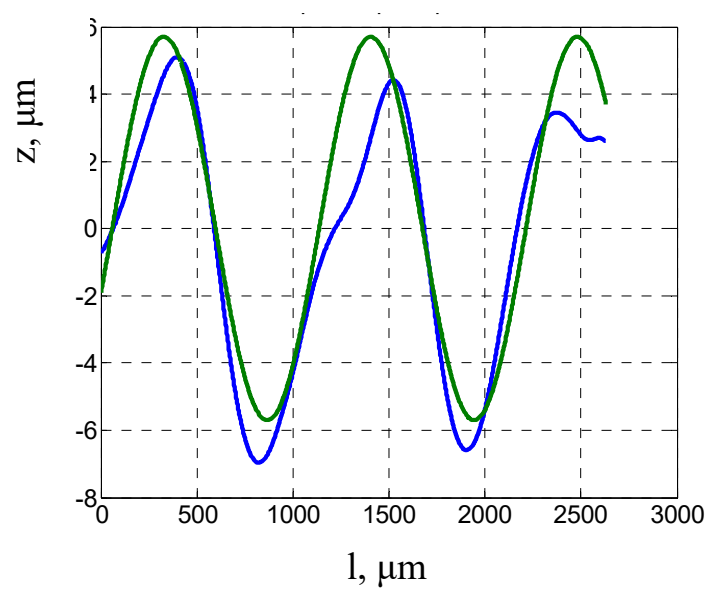

b)

Fourth pair of harmonics

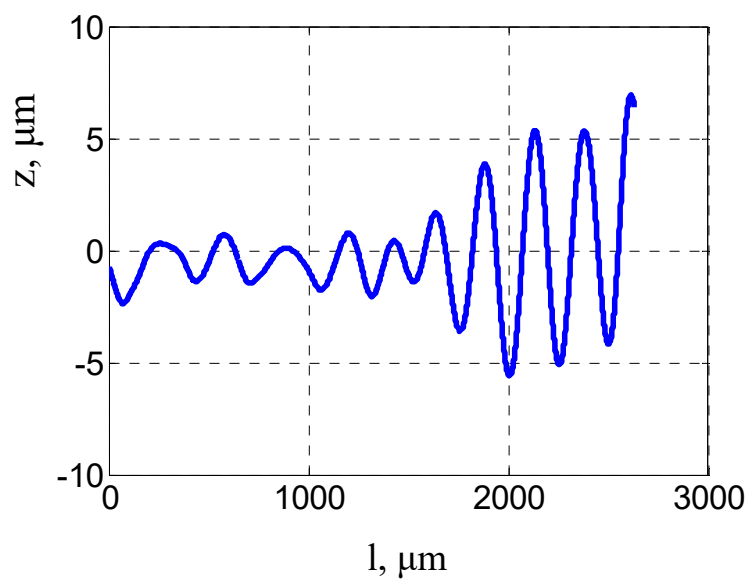

d)

Fifth pair of harmonics

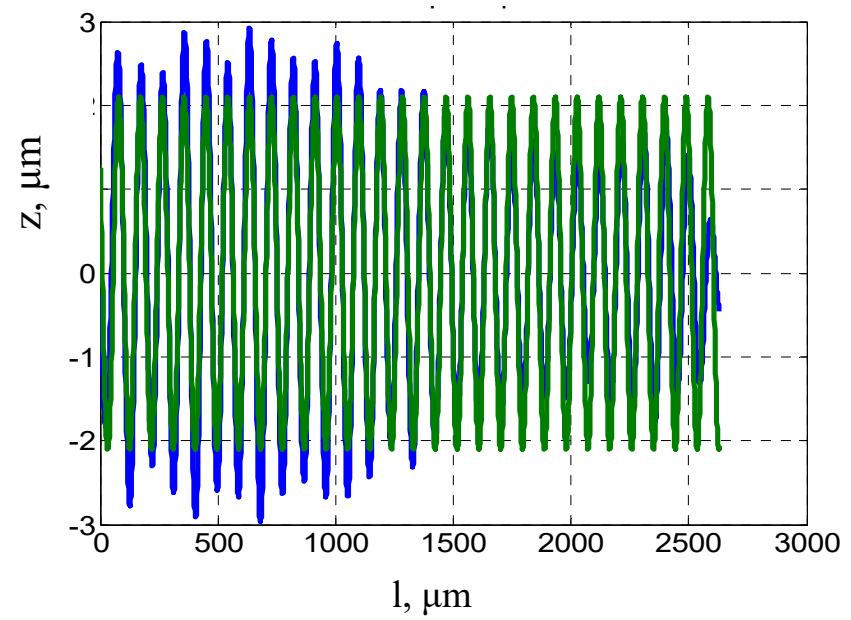

e)

Figure 3. Graphic results of the harmonic analysis of 10 eigenvectors with SVD of the profilogram of the working surface of a diamond grinding wheel with a grain size of $80 / 63 \mu \mathrm{m}$ 
First pair of harmonics

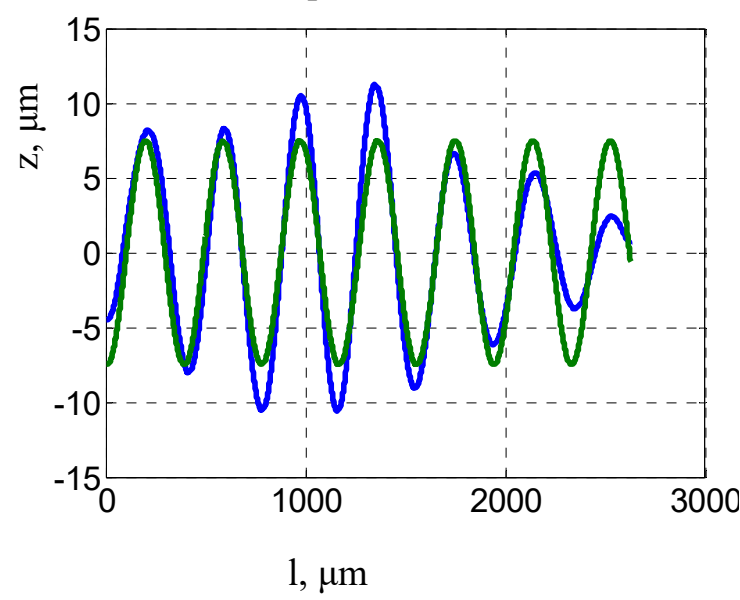

a)

Third pair of harmonics

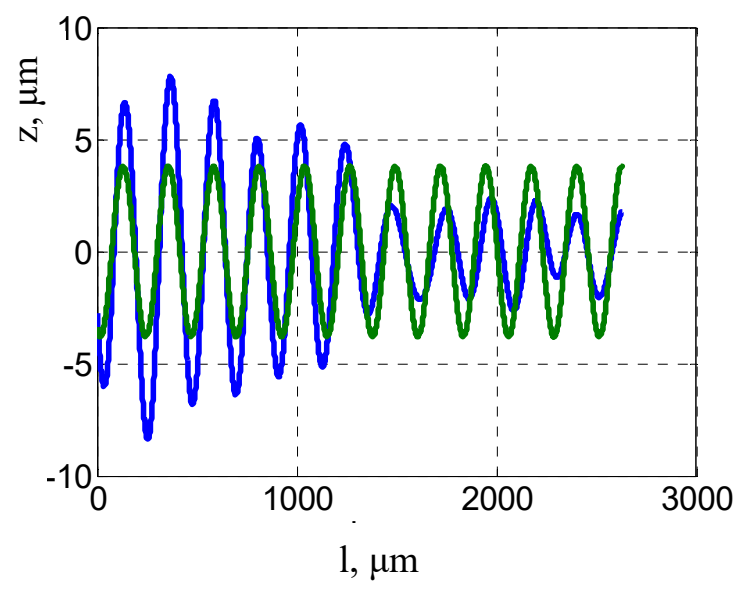

c)

Fifth pair of harmonics

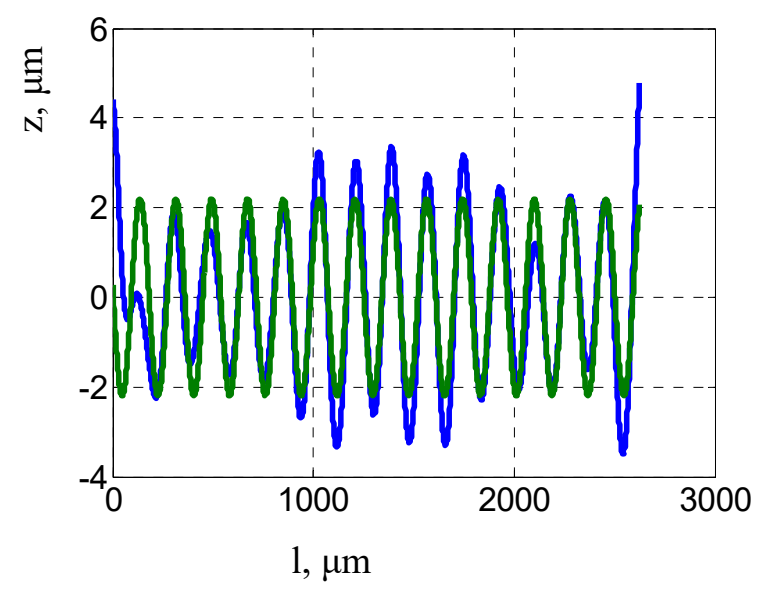

e)

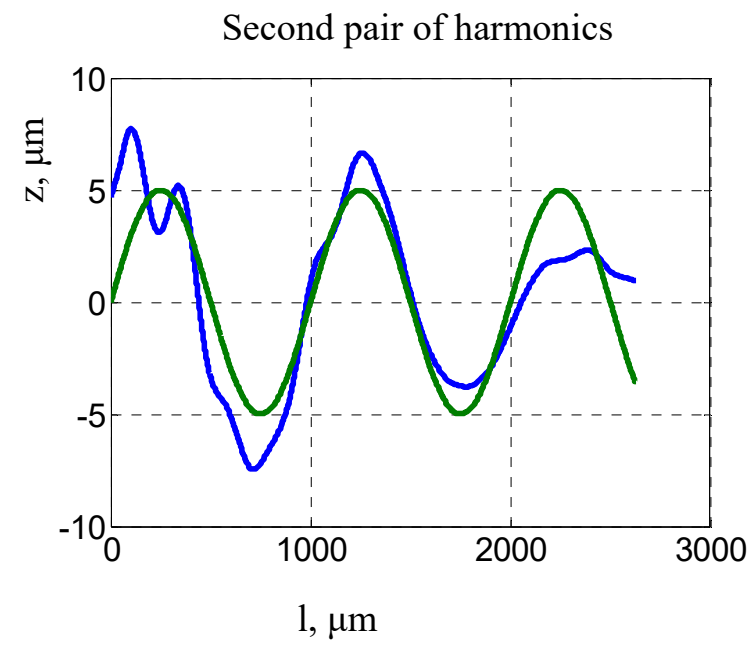

b)

Fourth pair of harmonics

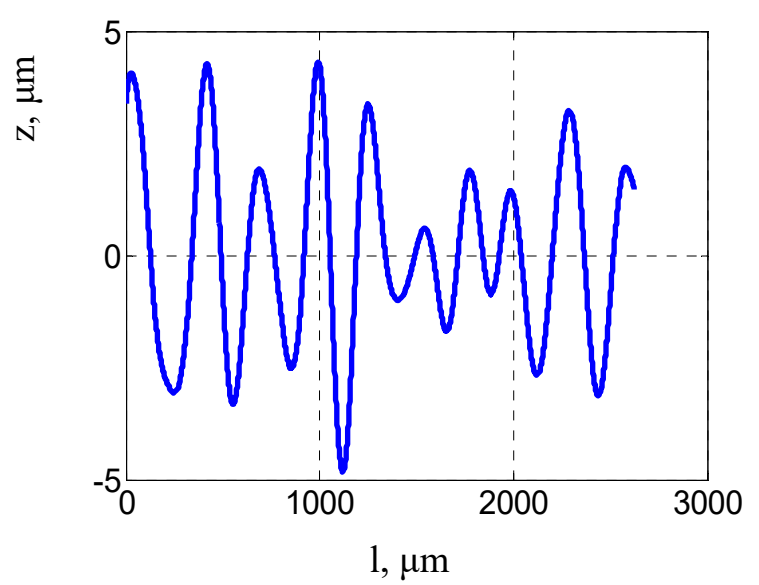

d)

Sixth pair of harmonics

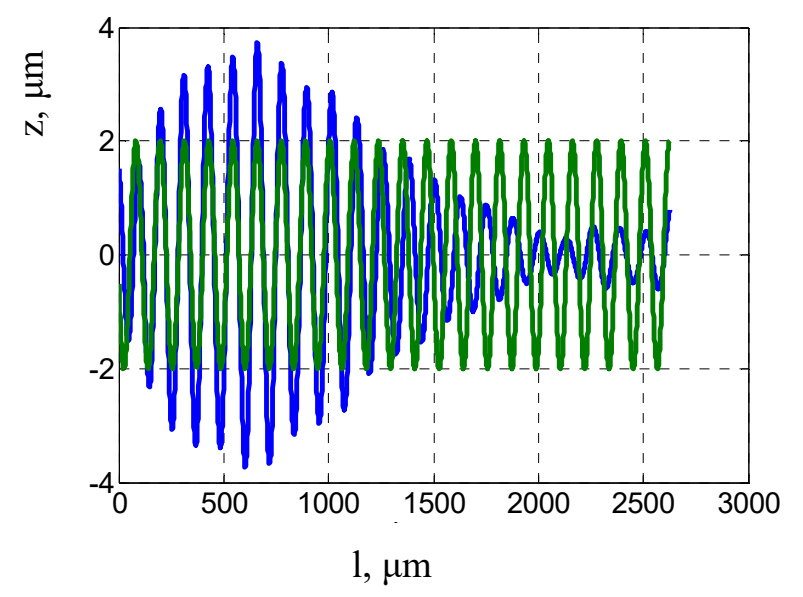

f)

Figure 4. Graphic results of the harmonic analysis of 12 eigenvectors with SVD of the profilogram of the working surface of a diamond grinding wheel with a grain size of 50/40 $\mu \mathrm{m}$ 
According to the results of harmonic analysis, the fourth harmonic is excluded from the analysis results. Figures 5. and 6. show the results of the

Periodic component

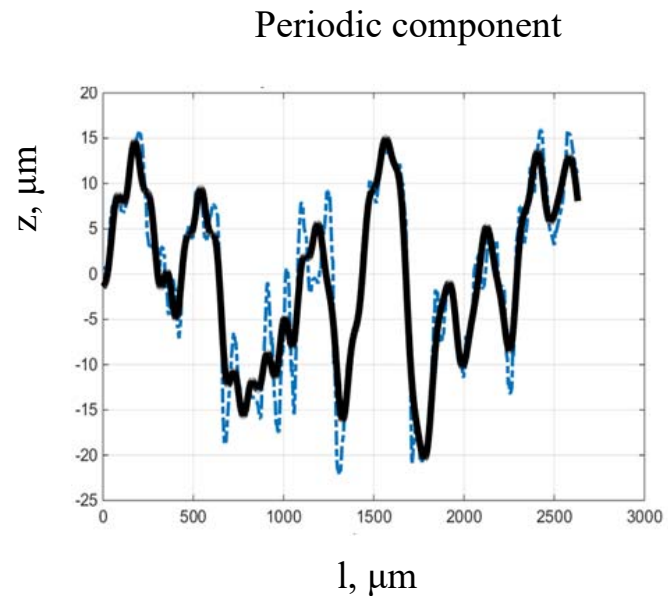

$1, \mu \mathrm{m}$ decomposition of the initial profilograms into periodic and random components. Experimental profilograms have dash-dotted line.

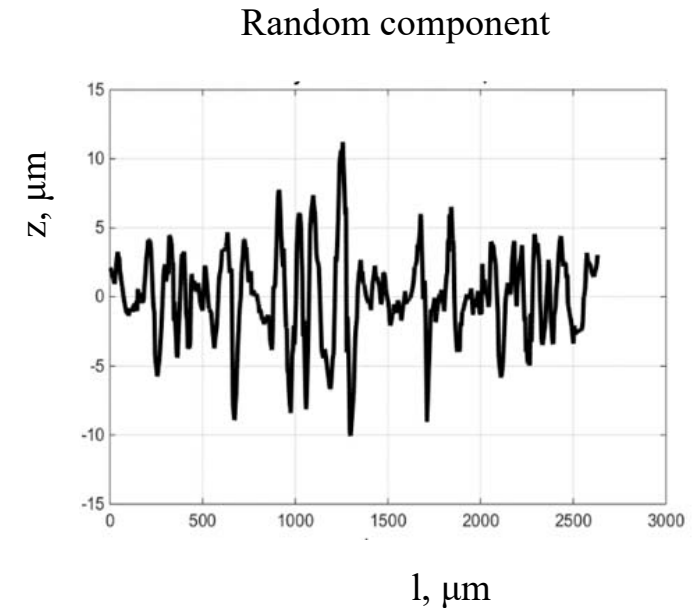

Figure 5. Periodic and random components for a diamond grinding wheel with a grain size of 80/63 $\mu \mathrm{m}$
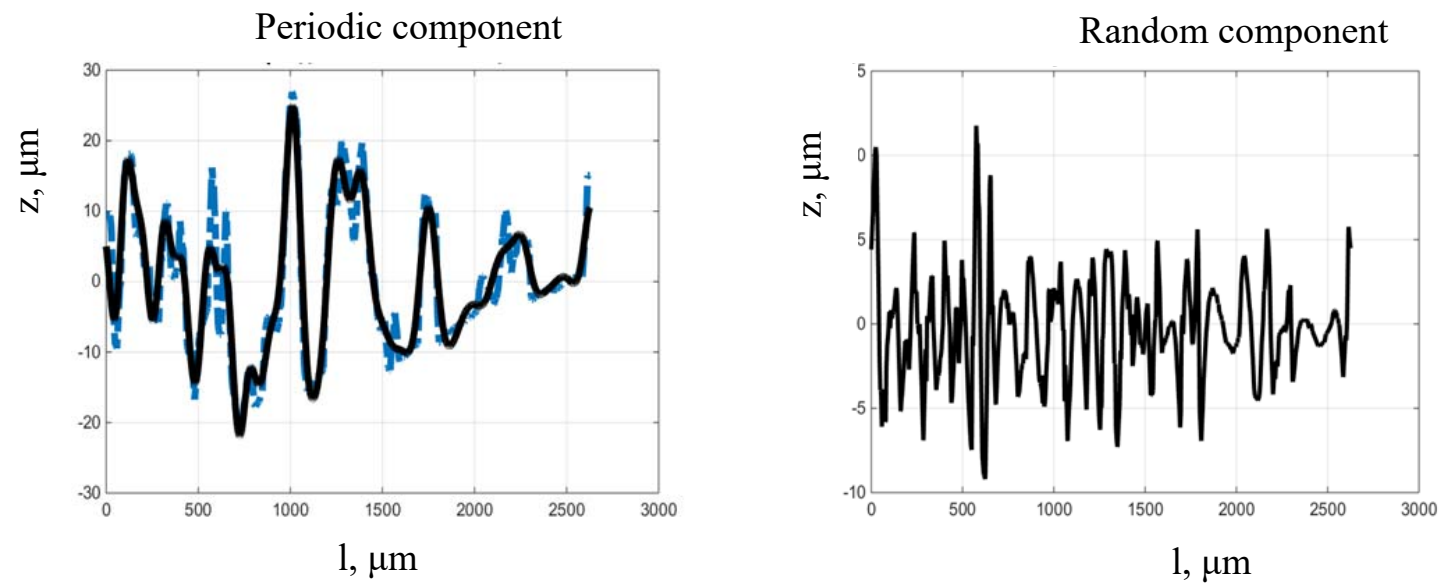

Figure 6. Periodic and random components for a diamond grinding wheel with a grain size of 50/40 $\mu \mathrm{m}$

The model of the random component is represented by the model of the stationary and ergodic random process obtained by the shaping filter method. Parameter identification of the shaping filter was conducted using the recursive least squares method [7].

The downfeed electric drive of the profiling electrode was modelled on the basis of a generalized electric machine theory. The mechanical part of the drive is a dual-mass elastic-dissipative model.

The parameters of the equivalent electrical circuit of the interelectrode gap were determined according to the oscillograms of currents and voltages experimentally measured at different values of the interelectrode gap with their subsequent processing using the System Identification Tool package included in Matlab. As a result of this, the parameters of the T-shaped equivalent circuit are obtained, taking into account the total output resistance of the working pulse generator and the interelectrode gap.
Since the current in the interelectrode gap has a pronounced oscillatory component, the equivalent circuit includes an oscillatory RLC circuit, shown in the Figure 7.

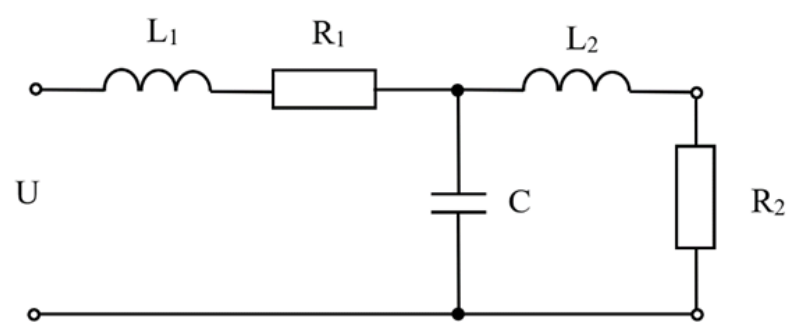

Figure 7. Periodic and random components for a diamond grinding wheel with a grain size of 50/40 $\mu \mathrm{m}$

Differential equation system of the transition process occurring in the T-shaped equivalent circuit has the following form: 


$$
\left\{\begin{array}{c}
L_{1} \frac{d I_{1}}{d t}+R_{1} I_{1}+U_{c}=U \\
L_{2} \frac{d I_{2}}{d t}+R_{2}(z) I_{2}=U_{c} \\
C \frac{d U_{c}}{d t}=I_{1}-I_{2}
\end{array}\right.
$$

Table 3. Parameters of the T-shaped equivalent circuit

\begin{tabular}{|c|c|c|c|c|c|}
\hline $\mathrm{N}$ & $\mathrm{R}_{1}, \mathrm{Ohm}$ & $\mathrm{R}_{2}, \mathrm{Ohm}$ & $\mathrm{L}_{1}, \mu \mathrm{H}$ & $\mathrm{L}_{2}, \mu \mathrm{H}$ & $\mathrm{C}, \mu \mathrm{F}$ \\
\hline short circuit & 3.76 & 0 & 153 & 73 & 12 \\
\hline $3 \mu \mathrm{m}$ & 3.76 & 0.23 & 154 & 77 & 13 \\
\hline $5 \mu \mathrm{m}$ & 3.76 & 1.91 & 152 & 81 & 15 \\
\hline
\end{tabular}

Table 3. shows that the resistance of the interelectrode gap $\mathrm{R}_{2}$ nonlinearly depends on its value. Since at a given generator voltage $U$ there is a limit value of the interelectrode gap $z$ at which an electric discharge does not occur, this dependence can be approximated by the following formula:

$$
R_{2}=\frac{a z}{b-z}
$$

where $a$ and $b$ are the approximation coefficients found by the least squares method, depending on the amplitude of the working pulse generator and the electrical parameters of the equivalent circuit.
Modelling of the process of electrical discharge machining is reduced to calculating both electric (current, voltage, and power in the interelectrode gap) and mechanical (gap, position of the diamond wheel, and its rotation speed) [8]. However, the selection of the optimal parameters of the pulse generator also depends on the characteristics of the diamond wheel; therefore, the creation of a topological surface of the wheel is also required. The block diagram of a dynamic model of the process of electrical discharge profiling of diamond grinding wheels is shown in the Figure 8.

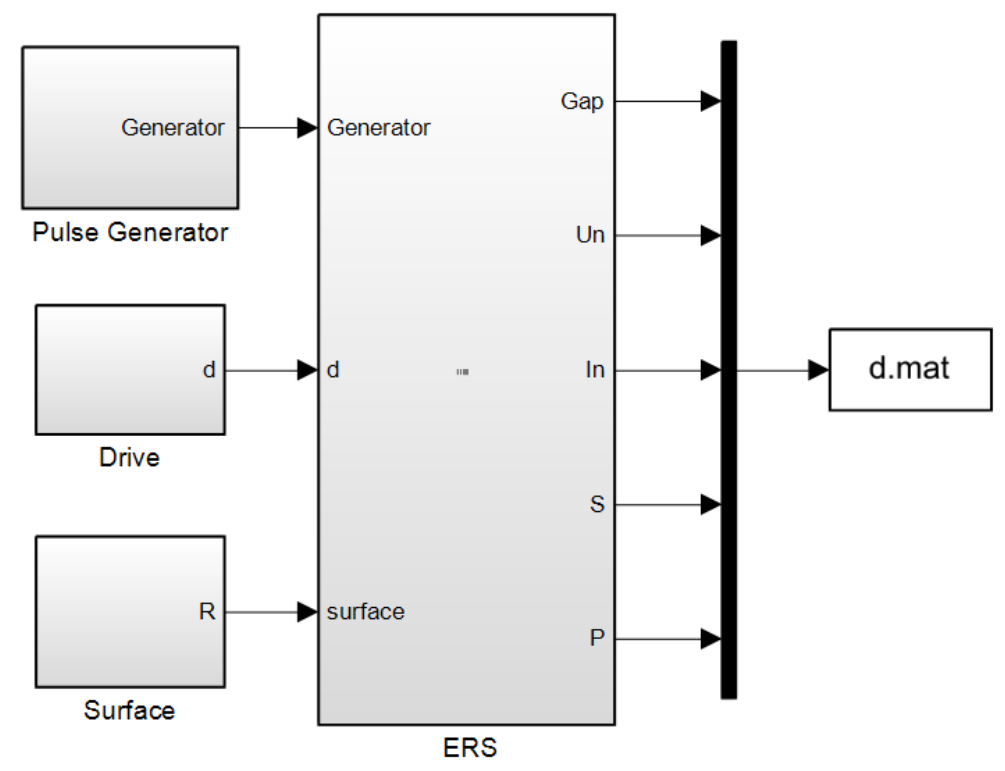

$\mathrm{d}$ is the delivery;

$\mathrm{R}$ is the diamond wheel surface;

$\mathrm{z}$ is the interelectrode gap;

Un is the voltage in the interelectrode gap;

In is the current in the interelectrode gap;

$\mathrm{S}$ is the removal of the ligament material from the diamond wheel;

$\mathrm{P}$ is the power in the interelectrode gap

Figure 8. Block diagram of the Simulink model of a dynamic model of the process of electrical discharge profiling of diamond grinding wheels with a system of automatic control of the interelectrode gap value 
This model consists of the following blocks:

1) «Pulse Generator» block is a rectangular pulse generator;

2) «Drive» block is a feed electric drive feeding a profiling tool electrode;
3) «Surface» block is a model of the diamond wheel surface, consisting of periodic and random components.

4) «ERS» block is the block of modelling of the electrical discharge machine on the basis of an electromechanical model.

Figure 9. shows the oscillograms obtained in Simulink; models, values of the gap, voltage, and power in relative units.

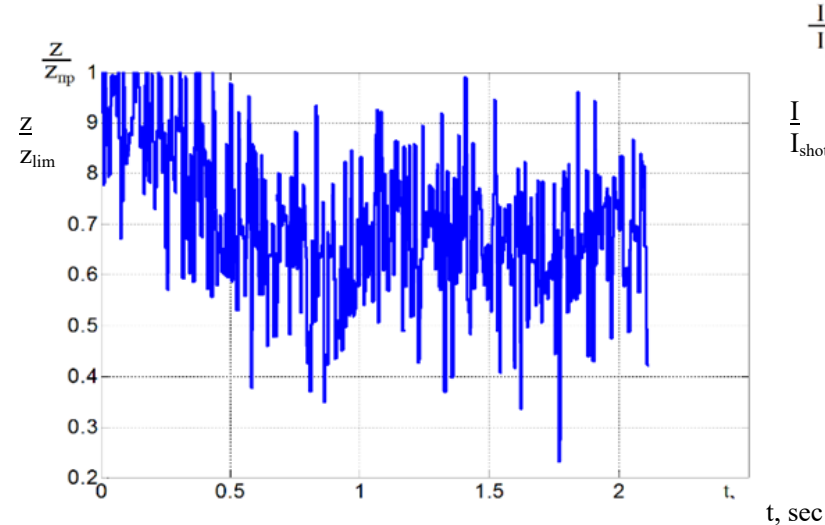

a)

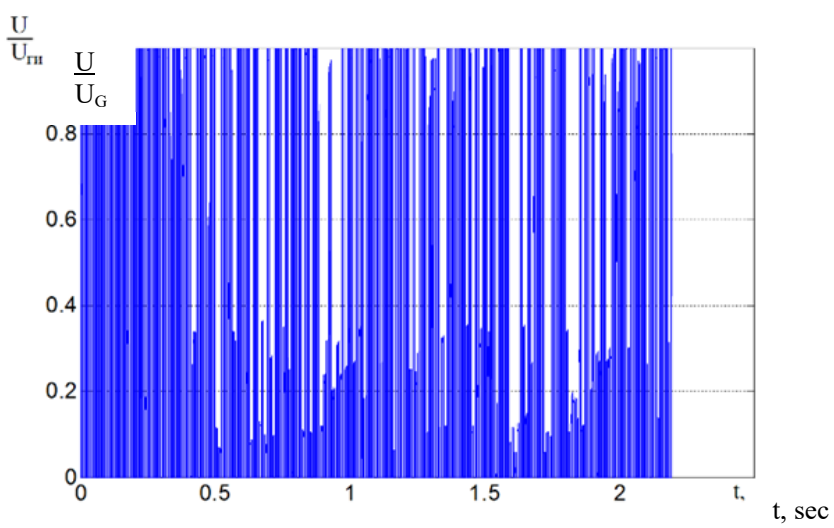

c)

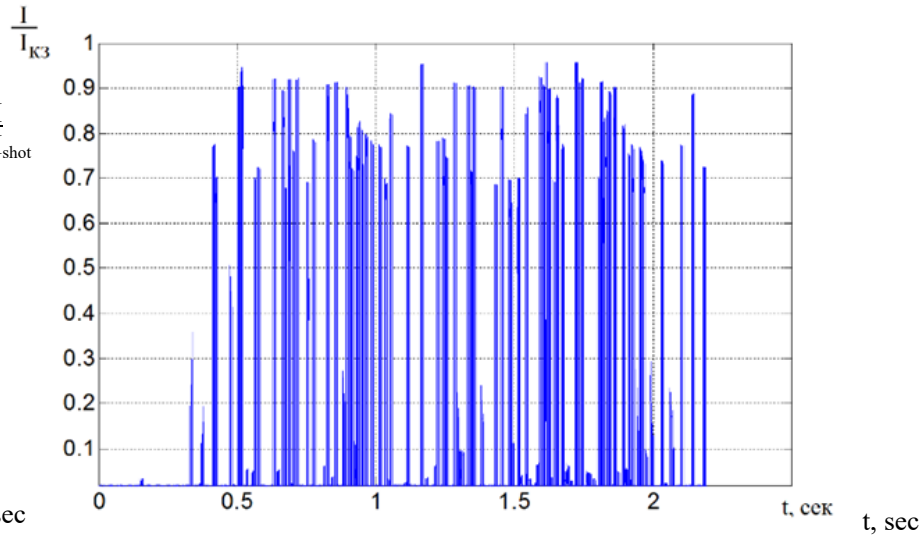

b)

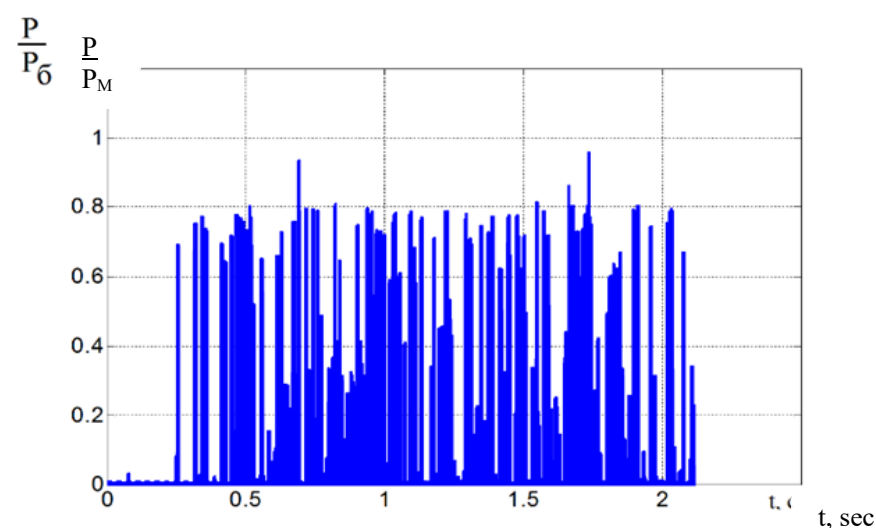

d)

Figure 9. Oscillograms of the electrical discharge machining process obtained in Simulink. Models: a) interelectrode gap; b) amplitude of the discharge current; c) amplitude of the voltage pulses; d) amplitude of the power pulses

The idle mode was selected for the gap unit, i.e. when current pulses do not pass between the tool and the workpiece. The maximum values are selected for a unit of current, voltage, and power. A comparative analysis of the results obtained from the Simulink model with experimental data shows a difference of no more than $14 \%$.

Figure 10. shows the dependence of the average power on the frequency of the technological pulse generator and the electrode gap in the instant period. 


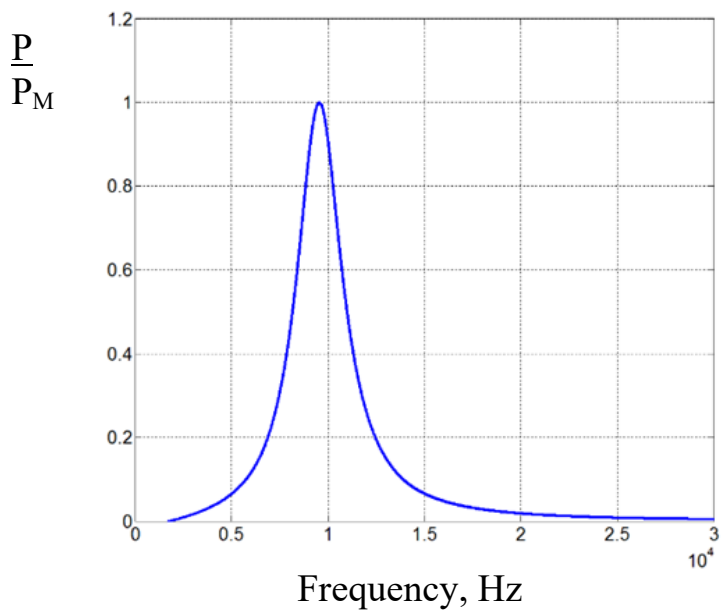

a)

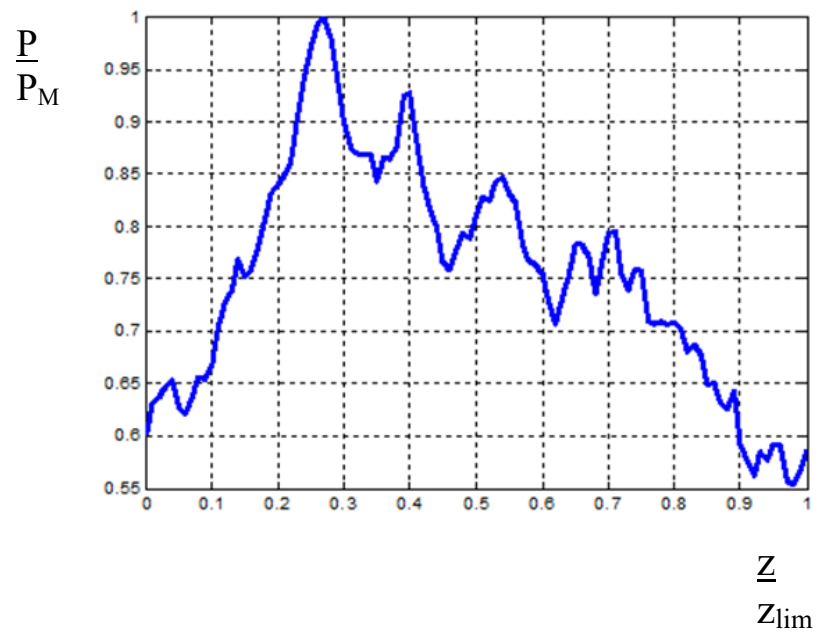

b)

Figure 10. Dependences of average power in an instant period of time: a) on the frequency of the technological pulse generator; b) on the interelectrode gap

Figure 11. shows the dependences of the average power on the interelectrode gap on its resistance. To

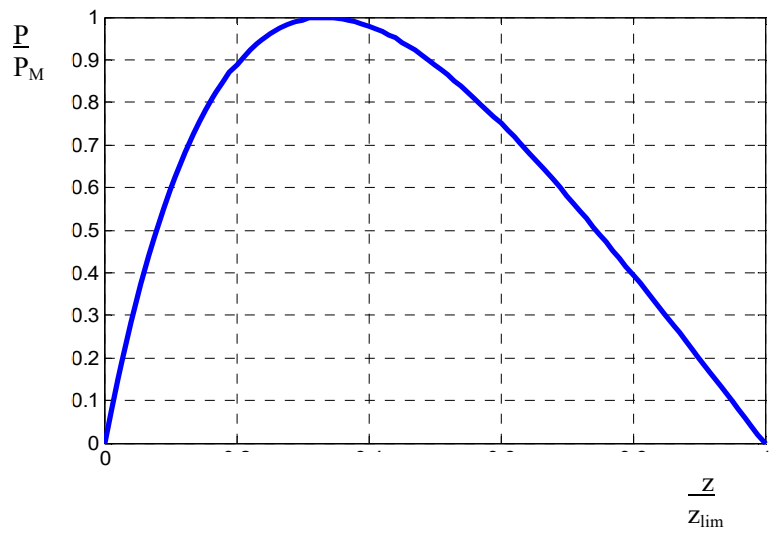

construct these curves, the recorded dependences of power at specific time periods were averaged.

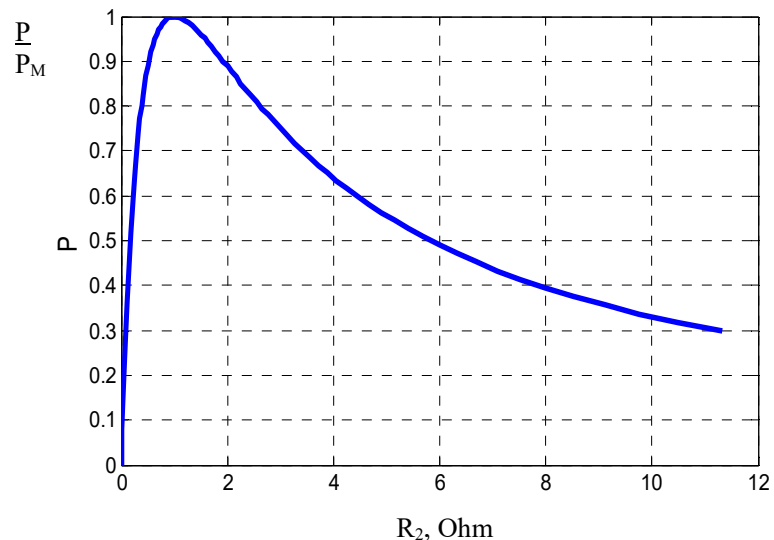

Figure 11. Dependences of average power on: a) size of the interelectrode gap; b) resistance of the interelectrode gap

As a result of modeling, the extreme dependence of the average power released in the interelectrode gap on the size of this gap was confirmed (Figure 12. a); the extreme dependence of the average power released in the interelectrode gap on the resistance of this gap was also established (Figure 12. b).

Studies conducted on the developed model, allowed establishing the following:

- increase in the roughness of the diamond wheel leads to a decrease in the extreme value of power, without changing the position of the extremum equal to half of the maximum gap, at which discharges still occur (Figure 12. a);

- inconsistency of the internal active resistance of the technological pulse generator and the active resistance of the gap leads to a decrease in the power released in the gap, and a decrease in the extremum without change in its value (Figure 12. b).

Therefore, in order to output maximum power to the gap, it is necessary to choose the amplitude of the discharge pulses in such a way that the interelectrode gap is equal to half of its limit value (Figure 12. c). 


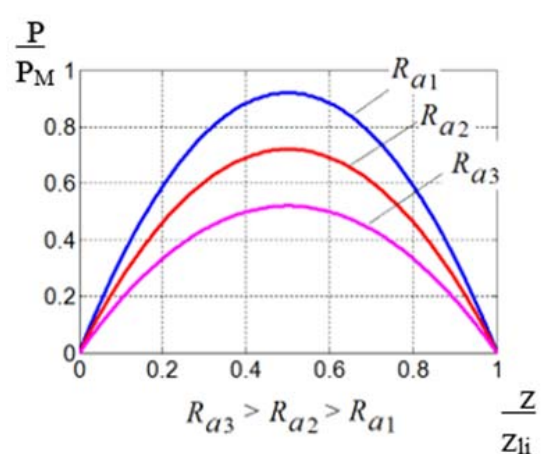

a)

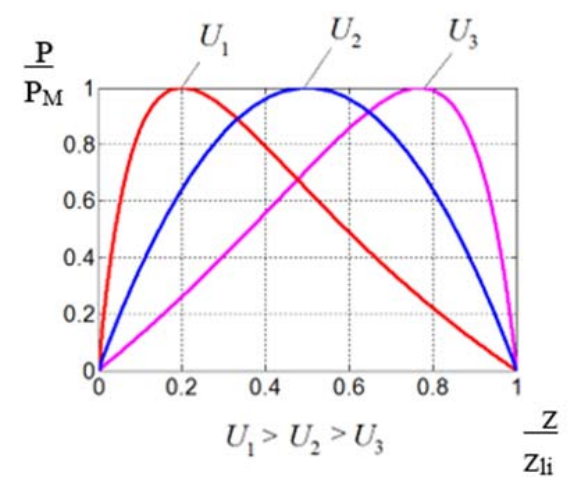

b)
$\underline{\mathrm{P}}$ Combined extreme characteristics

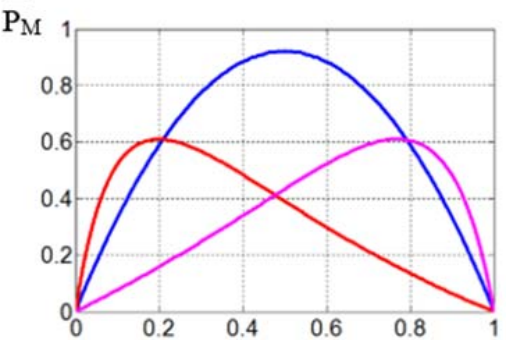

$\frac{\mathrm{Z}}{\mathrm{Z}_{\mathrm{li}}}$

c)

Figure 12. Shift of the extreme static characteristics: characteristic for various roughnesses Ra of the wheels (a); characteristic for various values of the voltage amplitude of the generator of working pulse U (b); combined curve (c)

\section{Development of the Extremum Search Algorithm}

Now we are going to consider a one-parameter extreme object defined by its extreme equation, in which we suppose that the unknown function $J$ depends on only one indefinite parameter $\alpha$ [9].

$$
Y=J(U, \alpha)
$$

Then the identification algorithm of extreme control consists of the following operations: identification of the parameter $\alpha$; calculation of the optimal value of the control parameter $U$ based on

$$
\begin{array}{cc}
\frac{\partial J}{\partial U}=0, & \text { recursive procedure: } \\
U(k+1)=U(k)-b_{k}\{J[U(k)+\Delta U, \alpha]-J[U(k)-\Delta U, \alpha]\}, k=0,1,2, \ldots
\end{array}
$$

The main problem in real-time realization of such algorithms is ensuring the stability of calculations of the solution of a system of linear algebraic equations in identification [10].

It is proposed to solve a system of linear algebraic equations and average the calculation results on the basis of the recursive least squares method [11]. The effectiveness of the proposed optimization algorithm is studied by the method of statistical testing. the solution of the equation and the movement of the object towards the extremum through the application of the optimal value of the control parameter $U$.

The drawback of the identification algorithm is the difficulty in identifying the unknown parameter $\alpha$, which can lead to significant errors in calculating the optimal value of the control parameter $U$ and the "yaw" of the extreme control system.

Therefore, in addition to the identification algorithm, search or step-by-step algorithms are used for searching the extremum of the objective function $J(U, \alpha)$.

According to the step algorithm, the control parameter $U$ is calculated on the basis of the

$$
y(k)=\sum_{i=1}^{n} a_{i}(k) y(k-i)+\sum_{j=0}^{m} b_{j}(k) u(k-j-s)+e(k)
$$

where $y(k)$ is the output of the model (time series) at the $k$ period of time; $\left\{a_{\mathrm{i}}(k), i=1, n\right\}$ are the parameters of autoregression; $\left\{b_{j}(k), j=1, m\right\}$ are the parameters of the moving average; $s$ is the discrete delay.

It is assumed that the channel for measuring the output of the object is affected by the noise $e(k)$, which is a centered random process with zero
Now we are going to consider a model of an object consisting of a series-connected extreme link (nonlinear part) with a priori unknown characteristics

$$
u=f(x)
$$

a pure delay link with a known delay value $\tau$, and a linear part described by n-order difference equation with corresponding initial conditions and timedependent coefficient: expected value and specified dispersion (white noise).

The value of the transfer coefficient and its sign can be determined using the recursive least squares method.

The algorithm of the recursive least squares method can be represented as follows [12]: 


$$
\left\{\begin{array}{l}
\hat{\theta}(k+1)=\hat{\theta}(k)+\gamma(k) e(k+1) \\
\gamma(k)=\mu(k+1) \boldsymbol{P}(k) \phi(k+1) \\
\boldsymbol{e}(k+1)=y(k+1)-\Psi^{T}(k+1) \hat{\theta}(k)
\end{array}\right.
$$

where $\hat{\theta}(k-1)=\left[a_{1}, \ldots a_{n}, b_{1}, \ldots b_{m}\right]$ is the vector of model parameters; $\Psi^{T}(k)=$ $=[-y(k-1), \ldots-y(k-n), u(k-d-1), \ldots+$ $u(k-d-m)]$ is the data vector;

$\mu(k+1)=\frac{1}{1+\Psi^{T}(k+1) \boldsymbol{P}(k) \Psi(k+1)}$ is the correction vector;

$\boldsymbol{P}(k)=\frac{1}{\left[\Psi^{T}(k) \Psi(k]\right.} \quad$ is the weighting matrix; $\boldsymbol{P}(k+1)=\left[\boldsymbol{I}-\gamma(k) \Psi^{T}(k+1)\right] \boldsymbol{P}(k) \quad$ is the weighting matrix calculated in the next step; $\boldsymbol{\phi}(\boldsymbol{k}+\mathbf{1})=\boldsymbol{\Psi}(\boldsymbol{k}+\mathbf{1}) ; \quad \widehat{\boldsymbol{\theta}}(\mathbf{0})=\mathbf{0} ; \boldsymbol{P}(\mathbf{0})=\boldsymbol{\alpha} \boldsymbol{I}$ are the initial values of variables.

The coefficient $k_{o}$ is calculated on the basis of the theorem on the final value of the discrete transfer function:

$$
k_{o}=\lim _{z \rightarrow 1} \frac{b_{0}+b_{1} z^{-1}+\ldots+b_{m} z^{m}}{1+a_{1} z^{-1}+\ldots+a_{n} z^{n}}=\frac{\sum_{j=0}^{m} b_{j}(k)}{\sum_{i=1}^{n} a_{i}(k)}
$$

The zero of the coefficient $k_{o}$ can be determined using one of the known methods: dichotomy method, method of golden section, Newton method, etc.

\section{Synthesis and Analysis of a System With an Extreme Controller}

To ensure two-coordinate control, it is proposed to use the method of coordinate raising (Gauss-Seidel method): this is the modification of the gradient method with a constant step, which allows reducing the total amount of calculations with a slight increase in the number of members of the minimizing sequence through the less amount of calculations [13], [14]. Each of the coordinates is calculated using the recursive least squares method. The structure of the extreme system of two-coordinate control is shown in the Figure 13.

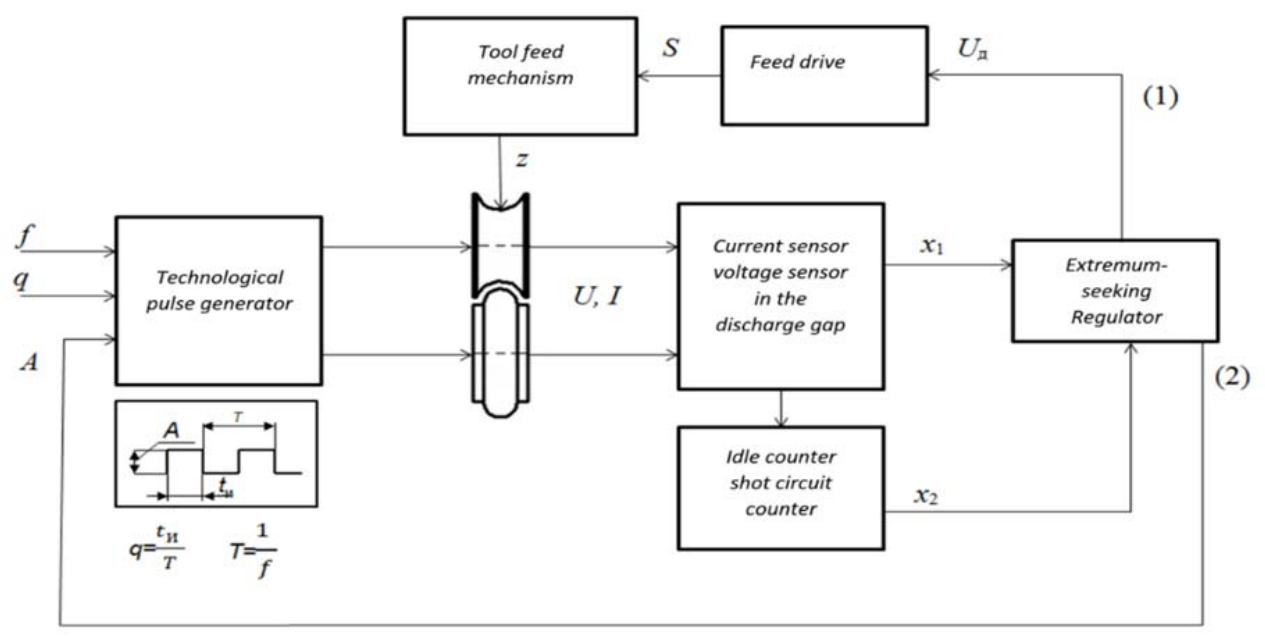

(1) is the control loop of the interelectrode gap;

(2) is the control loop of the amplitude of the voltage of the technological pulse generator.

Figure 13. System structure using two-coordinate control 


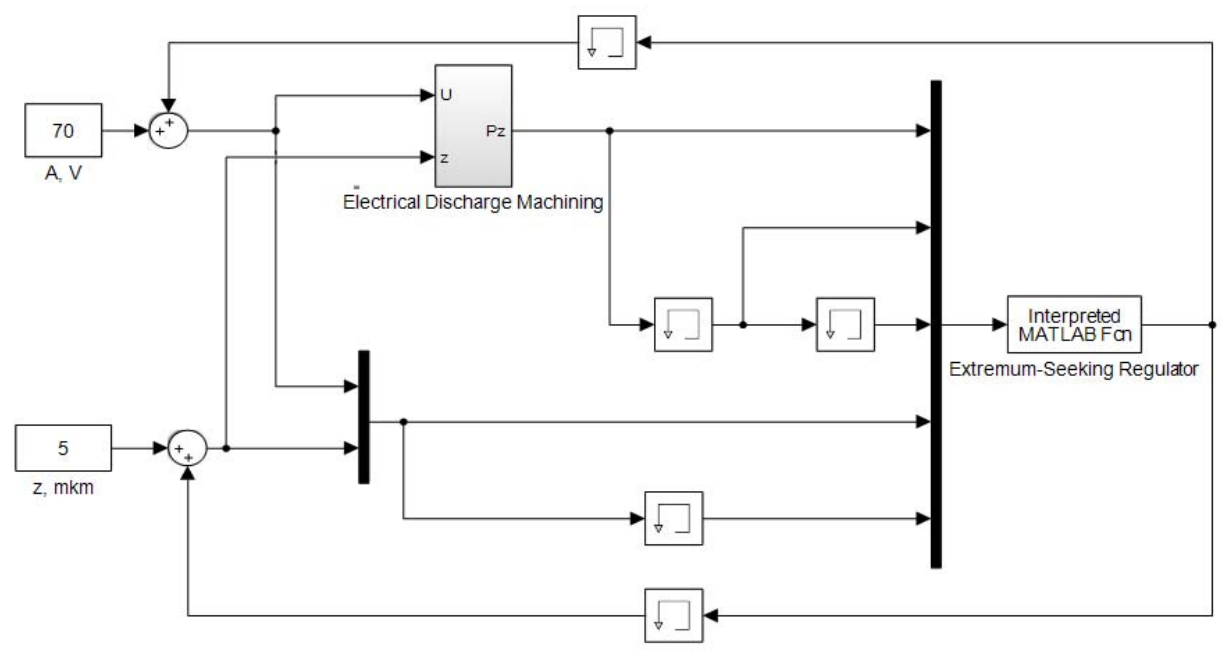

Figure 14. Two-coordinate control model
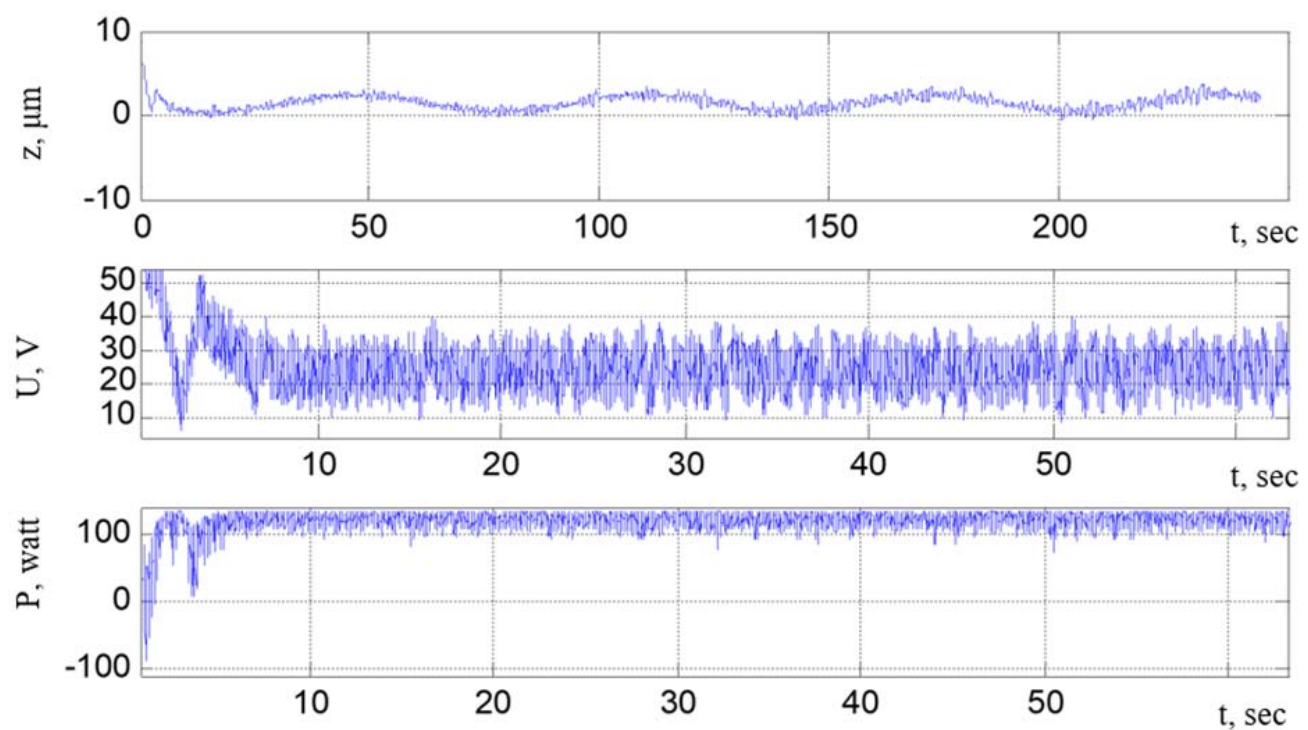

Figure 15. Modelled values of the interelectrode gap, the voltage amplitude of the technological pulse generator, and the average power released in the interelectrode gap

The analysis of the oscillograms shown in Figure 15. allows to conclude that even when exposed to strong noise, the level of which is comparable with the level of the input signal, the extreme control system keeps the coordinates of the object in the range of extreme values of its objective function.

Figure 16. shows the phase trajectory of the extreme control system in the coordinate space of a nonlinear link. 


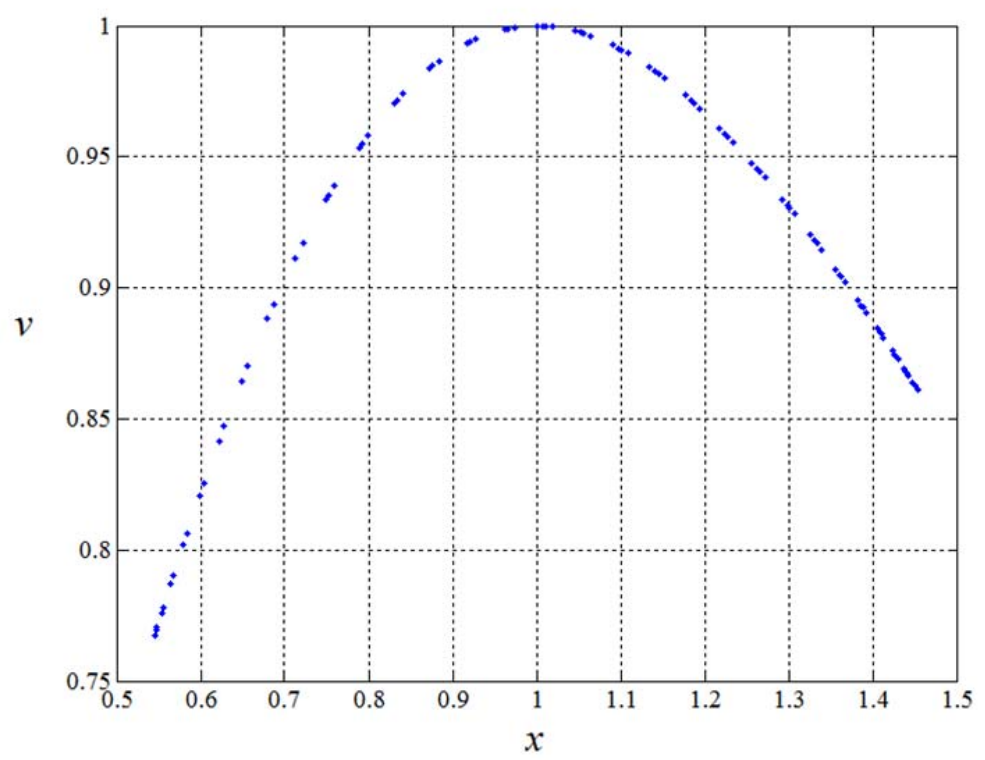

Figure 16. Modelled values of the interelectrode gap, the voltage amplitude of the technological pulse generator, and the average power released in the interelectrode gap

The phase trajectory is located in the vicinity of the point at which the objective function reaches an extremum (maximum). In spite of the high level of noise, the deviation of the system from the extremum point does not exceed $24 \%$, which confirms the effectiveness of the proposed algorithm.

Experimental studies were conducted on the proposed modes with circular feed of the profiling electrode on condition that the average power released in the interelectrode gap reaches the maximum value, as well as with the average value of the circular feed. Studies showed that profiling with extreme two-coordinate control provides an increase in machining accuracy up to $23 \%$ (Figure 17.).

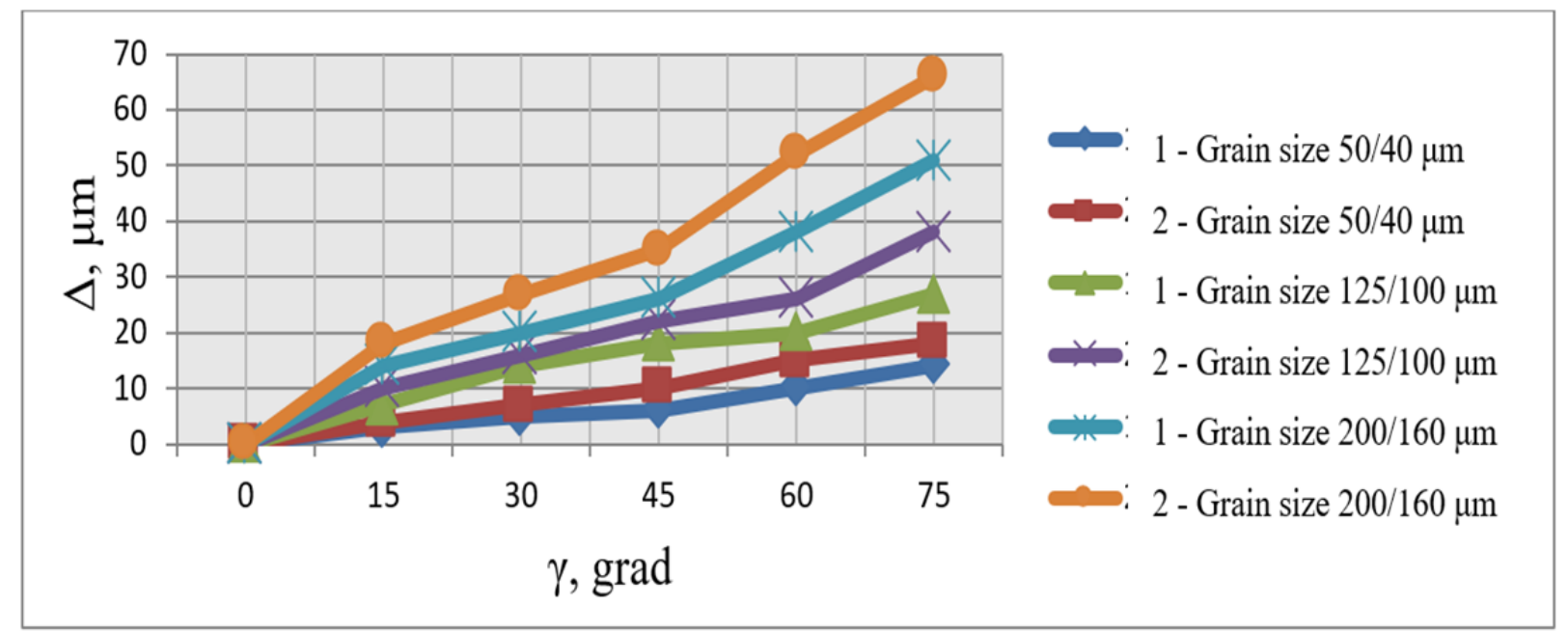

Figure 17. Dependence of the error of profiling of diamond wheels with various grain sizes of $100 \%$ concentration on the inclination angle of the local normal line with a circular feed of the electrode: 1 - on condition that the average power released in the interelectrode gap reaches the maximum value; 2 - with the average value of the circular feed

The following studies also showed that the productivity of the extreme system of electrical discharge profiling with two-coordinate control increased by $22 \%$. 


\section{Conclusion}

The process of electrical discharge profiling of diamond grinding wheels is an insufficiently formalized stochastic control object, the main drawback of which is low productivity. The selection of optimal processes significantly improves the quality indicators of this process. For this fact, we develop a generalized model of electrical discharge profiling of diamond grinding wheels.

An analysis of theoretical and experimental data allows concluding that the main indicator that reduces productivity is the low average power released in the interelectrode gap during electrical discharge profiling of diamond grinding wheels, which has an extreme dependence on the size of the interelectrode gap, and on the frequency and amplitude of technological pulses.

As a result, an algorithm was developed to search for the extremum of the static characteristic of an inertial object on current measurements of its input and output using the recursive least squares procedure, which assesses the transfer coefficient of the object, and then zero is found using direct methods of finding the function zero. As a result of modelling the algorithm operation, it was found that it provides convergent assessment values of the transfer coefficient, keeping the objects in the vicinity of the extremum point, even when exposed to strong interferences.

It is showed that profiling with extreme twocoordinate control provides an increase in machining accuracy up to $23 \%$, and the productivity of electrical discharge profiling process increased by $22 \%$.

\section{References}

[1].Avdeeva, O. V., Artamonov, D. V., Semenov, A. D., Nikitin, A. S. (2013). Automation of electric erosion machining using the method of extreme combined control. Proceedings of Universities. Volga region. Technical sciences, 4(28), 212-224.

[2].Bobtsov, A. A., Pyrkin, A. A., \& Kolyubin, S. A. (2014). Simple output feedback adaptive control based on passification principle. International Journal of Adaptive Control and Signal Processing, 28(7-8), 620632.

[3].Seal, A. (1998). Practical Process Control. London: Butterworth-Heinemann.

[4].Taran, A. V., Frantsuzova, G.A., \& Kharitonov, S.A. (2002). Control System of Electric Power Steering. Proceedings of the IASTED international conference "Automation, Control and Information Technology" (ACIT-2002), 121-124.

[5].Eliseev, Yu. S., \& Saushkin, B. P. (2010). Electrical discharge machining of aerospace products. Moscow: Bauman Moscow State Technical University Press.

[6]. Alexandrov, A. G. (1989). Optimal and adaptive systems. High School, Moscow, 263.

[7].Aleksandrov, F. I., \& Golyandina, N. E. (2004). Automation of allocation of trend and periodic components of time series within the method "Caterpillar"-SSA. Exponenta Pro. Mathematics in applications, 4, 54-61.

[8].Hewidy, M. S., El-Taweel, T. A., \& El-Safty, M. F. (2005). Modelling the machining parameters of wire electrical discharge machining of Inconel 601 using RSM. Journal of Materials Processing Technology, 169(2), 328-336.

[9].Yu, H., \& Ozguner, U. (2002, May). Extremumseeking control strategy for ABS system with time delay. In Proceedings of the 2002 American Control Conference (IEEE Cat. No. CH37301) (Vol. 5, pp. 3753-3758). IEEE.

[10]. Zhang, C., \& Ordóñez, R. (2011). Extremum-seeking control and applications: a numerical optimizationbased approach. Springer Science \& Business Media.

[11]. Izerman, R. (1984). Digital control systems. Moscow: World.

[12]. Semenov, A. D., Avdeeva, O. V., \& Nikitin, A. S. (2012). Extreme control algorithm based on the recursive least squares procedure. Proceedings of Universities. Volga region. Technical sciences, 1, 3-11.

[13]. Krstic, M. (1999, December). Towards faster adaptation in extremum seeking control. In Proceedings of the 38th IEEE Conference on Decision and Control (Cat. No. 99CH36304) (Vol. 5, pp. 4766-4771). IEEE.

[14]. Walsh, G. C. (2000, June). On the application of multi-parameter extremum seeking control. In Proceedings of the 2000 American Control Conference. ACC (IEEE Cat. No. 00CH36334) (Vol. 1, No. 6, pp. 411-415). IEEE. 